\title{
THE ROLE OF UNIVERSITIES IN THE KNOWLEDGE BASED SOCIETY
}

\author{
Andreea Simina RĂULEA, Constantin OPREAN, Mihail Aurel ȚîṬU \\ "Lucian Blaga" University of Sibiu, Sibiu, Romania \\ andreea.raulea@ulbsibiu.ro, constantin.oprean@ulbsibiu.ro, \\ mihail.titu@ulbsibiu.ro
}

\begin{abstract}
As a concept, knowledge covers vast ground and has multiple meanings. In the present day, it is frequently encountered through the term 'knowledge economy,' which is usually used to refer to the importance of knowledge as a contemporary commodity. Public awareness of the importance of intellectual property in the information age is essential to the successful implementation and growth of the knowledge economy. Most people do not have a very clear idea about the role of intellectual property in encouraging creativity and the importance to our economic well-being. While it is necessary to increase public awareness in this area, it will not be easy. Intellectual property is typically perceived as being incomprehensible because just a little part of the people has education in this field. IP education means the skills and competences that young people can be expected to acquire in the classroom that enable them to become familiar with intellectual property, understand its potential to generate income and economic growth and lead them to respect IP rights. This paper will present the role that universities play in the development of the knowledge based economy and the need to have more educational programs in this field.
\end{abstract}

\section{Keywords: intellectual property, education, knowledge based economy}

\section{Introduction}

In today's knowledge economy and globalised world, innovation and competitive advantage are key to ensuring worldwide economic growth. As manufacturing jobs have shifted increasingly to emerging economies, the contribution of the knowledge economy to European wealth and employment continues to grow.

In September 2013, a joint report by the European Union's Office for Harmonization in the Internal Market (OHIM) and the European Patent Office (EPO) found that $26 \%$ of EU employment and $39 \%$ of its GDP was generated by intellectual property rights-intensive industries [1].

But a study made by OHIM, through the EU Observatory on Infringement of Intellectual Property Rights, commissioned to gauge citizens' knowledge and perceptions of IP and IP infringements, in order to better understand them, and consequently design appropriate actions reveals that a large majority of EU citizens displayed strong support for IP, and yet considered that, on a personal level, breaking IP laws may be justified to cope with the consequences of limited purchasing power, and to protest against an economic model driven by a market economy and premium brands or legal offers not adapted to the digital market [2].

The problems caused by lack of IP awareness reach well beyond universities, and citizens and sometimes have devastating financial effects. 
In the long run, the competitiveness of an economy depends on the innovative potential won through the valorisation process of intellectual property rights. But we can talk about this only in the context where there is a solid education in the field of intellectual property.

IP education should include references to skills and competencies that young people can be expected to acquire in the classroom that enable them to become familiar with intellectual property, understand its potential to generate income and economic growth and lead them to respect intellectual property rights, whether their own or those of others. It is a process that supports pupils in becoming future IP creators.

The Romanian economy in the process of "transition" stabilizing the macroeconomic framework requires, in such a way as to be able to address all relevant aspects and needed restructuring and modernization of the Romanian society. Considering the current situation, the only way to ensure economic development and to create prerequisites for increasing the competitiveness of national industry is by applying the model of development based on innovation and one of the central strategic elements should be an educational system. In this way will be created a framework in which well-being will be a constant that will last in the long term.

Industrial countries' history has shown that the success of an economy at macroeconomic level, depends on development of the innovation process, and the practice confirmed that in order to promote a process of innovation at the national level it requires more knowledge, applied science, embodied in the new technologies, new products and services, a new form of presentation of new products, a new functional structure, a new organizational form, new management methods and organization of education, in short to develop on the basis of creative efforts, a process leading to innovation: creating value by knowledge valorisation.
So, the main role of the organizations is represented by protection and integration of specialized knowledge [3].

\section{The need for intellectual property education in Romania}

The increased interest in protecting intellectual property rights and thus for innovation can be achieved based on a strategy aimed at making human resource aware about the importance of these issues in relation to the economic development.

Universities need to give heed at preparing their students to be productive citizens of the innovation economy, and that includes giving more attention to IP education. In particular, graduate students in science, technology, engineering, and math and all other specializations should receive instruction on the nature, purpose, and protection of IP. This does not mean turning them into patent, copyright, trademark, and trade secret specialists. But it does mean ensuring that each of them receives at least a modest amount of training regarding their IP rights and obligations.

In this respect, the Romanian Ministry of Education, starting with the academic year 2015-2016, proposed the introduction of four new optional disciplines among which include the one called "education for intellectual property rights". It proposes exposure to high school students to the issue of intellectual property rights, involving youth in the development and in the promotion of projects for copyright or other intellectual property rights, preparing high school students for appropriate behaviour in respect to sustainable development [4].

The introduction of at least one teaching specialty discipline would increase awareness concerning the importance of intellectual property in the current life, with an emphasis on creativity and the development of new technologies. This academic discipline will fit within the context in which the European Commission 
encourages the promotion of the concepts of open education.

In this context, IP education goes beyond the narrower concept of promoting theoretical knowledge and understanding of IP components such as copyright, patents, trademarks and designs. When applying this to school curricula, the focus is not only on knowledge but also on how knowledge applies to students' everyday lives. IP education will prioritize learning outcomes that deliver skills and competencies that young people can be expected to acquire in the classroom. IP education will lead in time to a competitive economy (figure 1).

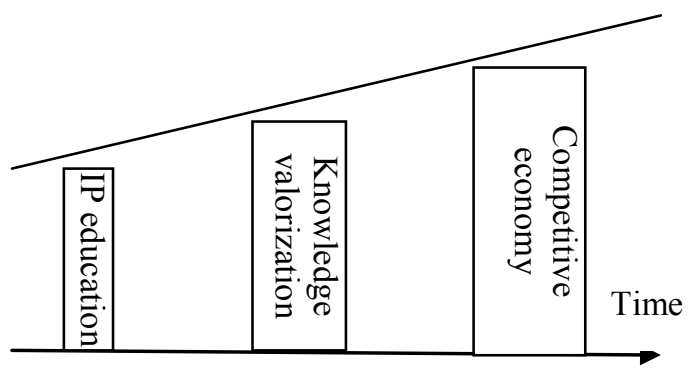

Figure 1: IP education and economy

\section{The role of universities and intellectual property development}

In order to emphasize the impact of the education in the field of intellectual property in universities we have made a documentary research based on studying the literature available in this field.

Firstly, we highlighted the role of the universities in the current context, which are regarded as both formative institutions, scientific research centres, sources of technological innovation, commitment to civil rights, social justice and reforms.

These multiple roles make it very hard to establish a mission for the university as a whole entity and hence has a framework for action that should be followed in order to meet the needs overall.

All of these roles mentioned in previous rows represent characteristics of an institution that aspires to set up the future, an institution that braves history through periodic review of the background and assumptions. Today, the Romanian universities, and not only, are facing with specific challenges such as: expanding education through continuing education, academic training and increasing the importance of the traditional post-bachelor's studies, market globalization, the internationalization of qualifications, multiplying the higher education providers, the expansion of higher education distance learning contouring constructive transition from training individuals to training people. All these aspirations show that the role of universities is to create a better place for the future and this is possible only by targeting the needs of today society that is "hungry" of new technologies and products.

Investment in research, development and innovation in valorizing intellectual property rights is a key factor determining long-term economic development. Thanks to research and innovation new products and processes that contribute to the overall well-being of a nation are created.

In order to bring economic benefits, have developed various organizational forms of the universities, which include intellectual property offices, technology transfer, licensing, incubation and spin-off.

In principle, universities are required to carry out its mission of education, research and service. But, the purpose and function of the university have always been knowledge and wealth creation for the benefit of the public. This model has evolved to the one which concerns the university as a major player in the economic development process.

More than ever before, universities should take into consideration better ways to manage intellectual property and patenting. Thus, maintaining the basic functions of education and theoretical development, they should increase the attention directed to the creation of wealth, not only for society in general, but in particular by generating income for these universities.

Thus, changing the structure and functions of universities has become a crucial necessity in turning the flow of 
knowledge into new sources of industrial innovation [5].

In order to support the aforementioned, shall submit its conclusions on a study of 1000 students from 115 American universities regarding the relationship between universities and industry, which outlines seven objectives of universities [6]:

-Encourage research-orientated university;

-Promotion of patentable inventions;

-Participation in the regional economic development;

-Intensifying commercialization of academic research results;

-Stimulation of university consultancy given to industry;

-Providing support for start-up companies based on advanced technology;

-Stimulation of capital investments into companies based on academic research. Business transformations to come in universities and in the academic and respectively in economic world constitute the subject of intense debate in recent years [7].

As regards Romania, cannot say very much about the excellence in research and those adjacent to this area because of the low interest in protecting intellectual property rights (figure 2 ).

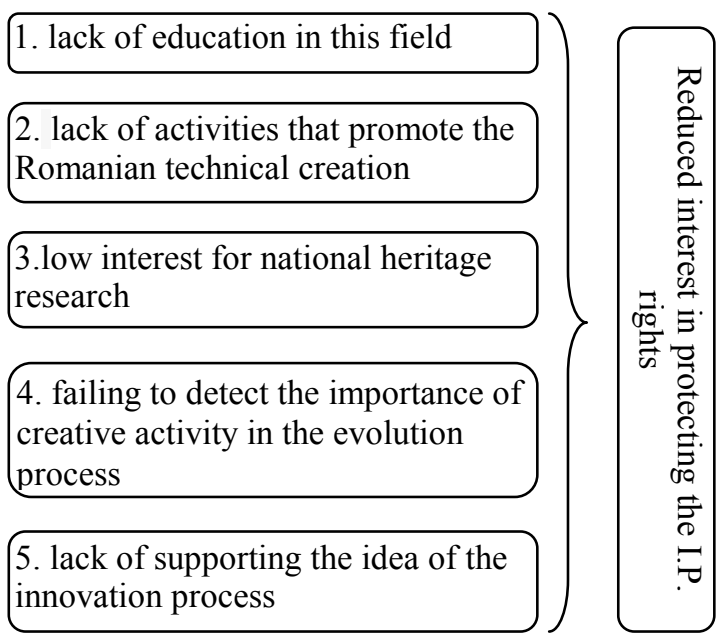

Figure 2: Causes of low interest to protect I.P. rights

Making an analysis of the competitiveness indicators, in terms of attracting talents Romania ranks 52 out of 109 , that being a relatively good score considering Bulgaria's position on 44. Also, according to the study, we are in the top 10 in terms of migration of inventors from Romania to US in particular. From the point of view of the opening of the attraction of talents and putting up some new business we are ranked number 92 . From the point of view of entrepreneurship Romania's position is a better one, "new product entrepreneurial activity rank and new business density 27" which represents "a glimpse of hope". The Romania's position is a reflection of the expenditure on research and development (table 1).

The problem in this moment is that talented people leave and the real value is created elsewhere and captured by others [8].

Currently, reports and statistics conducted globally converge in supporting the theory that human capital is a factor of economic growth [9], [10], [11].

Over time, researchers have emphasized the importance of the higher education in human capital formation and economic growth. For example, there are studies that have shown that there is a more pronounced growth in countries where it is well developed the system of higher education [12].

Beyond the many studies and models built over time in order to demonstrate the connection between education and competitiveness, it is obvious that its role has been recognized also by international bodies concerned with measuring the economic competitiveness of countries and of their ranking according to level and its dynamics. There are two international organizations with preoccupations in this field: the World Economic Forum (World Economic ForumWEF), which published starting in 1979 The report on Global Competitiveness, and the Institute for Management and Development (International Institute for 
Management Development-IMD) which, since 1989, edit the World Competitiveness Yearbook.

The indicator of Global Competitiveness (Global Competitiveness Index) conducted by the WEF in structure based on twelve pillars that relate to: public and private institutions, infrastructure, macroeconomics, health and primary education, higher education and training, the efficiency of markets, labour market efficiency, financial market complexity, technology, markets dimensions, business complexity and innovations.

Analysing these pillars, we can see that education is reflected in many of them. Higher education can be found in the form of various indicators, either directly or indirectly, in the case of indicators' "public and private institutions" regarding the quality of educational institutions and those that have a role of policy-making and policy implementation in the field and the fact that they put its mark on the competitiveness.

Table 1. Total expenditure on research and development, financing sources and sectors of performance in the 2014 (million lei, current prices)

\begin{tabular}{|l|c|c|c|c|c|}
\hline $\begin{array}{l}\text { Funding } \\
\text { sources/sectors of } \\
\text { performance }\end{array}$ & Total & $\begin{array}{c}\text { Business } \\
\text { sector }\end{array}$ & $\begin{array}{c}\text { Governmental } \\
\text { sector }\end{array}$ & $\begin{array}{c}\text { Higher } \\
\text { education } \\
\text { sector }\end{array}$ & $\begin{array}{c}\text { Private } \\
\text { non-profit } \\
\text { sector }\end{array}$ \\
\hline Enterprises & 841,2 & 627,5 & 186,7 & 26,9 & 9,5 \\
\hline Public funds & 1240,8 & 201,4 & 818,7 & 214,4 & 6,3 \\
\hline $\begin{array}{l}\text { Higher education } \\
\text { establishments }\end{array}$ & 36,9 & 1,9 & 1,2 & 33,8 & - \\
\hline Private non-profit & 2,4 & 0,2 & 0,6 & 1,0 & 0,6 \\
\hline Overseas & 4434,4 & 228,4 & 90,6 & 112,9 & 2,5 \\
\hline Total & 2555,7 & 1059,4 & 1097,8 & 389,6 & 9,5 \\
\hline
\end{tabular}

Source: National Institute of Statistics, Press release no. 291/2015

Another indicator is the "education and training". As regards the "efficiency of the labour market" is evident in the quality of labour force dependency of the education system. Within this pillar can be found including the phenomenon of brain drain. If we speak of technology must be highlighted technological capacity of a country and that it is determined by the quality of higher education in universities. In the same context, the indicator related to innovation, highlighting the fact that it cannot exist without institutions of research, workforce of highly skilled scientists and engineers, research and development centres that are able to exploit relationships between universities and businesses, and without intellectual property protection.

\section{Conclusions}

The economic importance of intellectual property is gaining recognition and attention and cannot be overstated and, indeed, it is receiving a great deal of attention worldwide. To advance the cause of the benefits of intellectual property protection at the national and international levels, education in intellectual property is required and must be advocated. We must make individuals, industries, and governments aware of the concept of intellectual property, and only then can they take positions on the issue in order to effect change.

In the developing world, the question of intellectual property and its education is a murky one. While countries are making an effort to curb the exploitation of IP and to educate their citizens, the concept is catching on only slowly. Many developing nations face a funding crisis when it comes to creating programs on IP awareness.

It is the time to reorganize 
universities and is obviously the time of many changes for the better. But first and foremost, it is awareness time of importance of intellectual property for development and growth on all levels. It is the time to look at the statistics and act accordingly in order to bring Romania into top ranks related to competitiveness.

In a globalized world, universities are seen increasingly more as producers of knowledge, innovation, technology and qualified workforce from a strictly economic point of view, thus contributing to the creation of wealth and competitive advantage. It is also expected that universities generate revenue due to high demand of superior education that comes from all over the world. But this should be looked at also through the fact that universities do not just produce technology and manpower, but they form people, individuals, an active part of the society. Thus, universities have the responsibility to create professionals who contribute to the long-term national well-being. The university is the central element in the generation of new ideas to influence society. Thus, universities are required to realise the need for themes and studies that evaluate the impact of new knowledge.

This approach requires the integration of a study program centred on intellectual property which represents a first step in developing a company aware of the power of innovation, knowledge and intangible resources. The universities can create an entrepreneurial culture and a culture of innovation in particular, they can promote innovation as a strategy for longterm success and can ensure competitiveness in an era dominated by globalization.

\section{References}

[1] https://euipo.europa.eu/ohimportal/documents/11370/80606/IP+Contribution+study

[2] European Citizens and Intellectual Property: Perceptions, Awareness and Behaviour (2013): https://oami.europa.eu/ohimportal/documents/11370/80606/IP+perception+study

[3] Țîțu, M., Oprean, C., Boroiu, A. Cercetare experimentală aplicată în creșterea calității produselor și serviciilor, Bucharest, Agir Publishing, 2011.

[4] http://www.edu.ro/index.php/pressrel/22812

[5] Chang Yuan, Managing academic innovation in Taiwan: Towards a scientific-economic framework, Technological Forecasting \& Social Change 73, pp. 199-213, 2006.

[6] Azagra-Caro, J.M. et al. Faculty support for the objectives of university-industry relations versus degree of $R \& D$ cooperation: The importance of regional absorptive capacity, Research Policy 35, pp. 37-55, 2006.

[7] Jain Sanjay et al. Academics or entrepreneurs? Investigating role identity modification of university scientists involveed in commercialization activity, Research Policy 38, pp. 922-935, 2009.

[8] The Global Competitivity Index 2015-2016, http://globalindices.insead.edu/gtci/documents/INSEAD_2015-16_Full_Book_Ebook.pdf

[9] Gyimah-Brempong, Kwabena, Paddison, Oliver, Mitiku, Workie, Higher education and economic growth in Africa, The Journal of Development Studies, No. 42, pp. 509-529, 2006.

[10] Keun, Lee, Byung-Yeon, Kim, Both institutions and policies matter but differently for different income groups of countries: Determinants of long-run economic growth revisited, World Development, Vol. 37, Issue 3, pp. 533- 549, 2009.

[11] Krueger, A.B., Lindahl, M. Education for growth: Why and for whom?, Journal of Economic Literature, American Economic Association, Vol. 39, Issue 4, pp. 1101-1136, 2001.

[12] Matton, Richard, Can higher education foster economic growth?, Chicago Fed Letter, No. 229, 2006. 